\title{
SERANGAN RAYAP COPTOTERMES SP. PADA TANAMAN MERANTI MERAH (SHOREA LEPROSULA MIQ.) DI BEBERAPA LOKASI PENANAMAN DI KALIMANTAN TIMUR \\ Termites Attack of Coptotermes Sp. on Red Meranti (Shorea Leprosula Miq.) at Several Planting Sites in East Kalimantan
}

\author{
Ngatiman \\ Balai Besar Penelitian Dipterokarpa, Samarinda \\ Jl. A.W. Syahranie No.68, Sempaja, Samarinda; Tlp. (0541) 206364, Fax (0541) 742298. \\ e-mail : ngatiman_diptero@yahoo.com \\ Diterima 09 Januari 2014, direvisi 28 Mei 2014, disetujui 05 Juni 2014
}

\begin{abstract}
Termites attack Coptotermes sp on red meranti (S. leprosula Miq.) plantation causes death. This study aims to obtain percentage of attacks and plants mortality of termites attack Coptotermes sp.. The method used is to establish some research plots in planting sites of red meranti, among others: PT Inhutani I, Mentawir; around nursery UUCD, Samboja; KHDTK Sebulu and KHDTK Samboja;. The results showed that the percentage after mites attacking plants S.leprosula in PT Inhutani I, Mentawir attack percentage was $44.24 \%$, with the percentage of dead plants $10.61 \%$ in around nursery UUCD, Samboja was $27.02 \%$ with the percentage of dead plants $18.91 \%$, in KHDTK, Samboja attack percentage was $4.37 \%$ with the percentage of dead plants $1.09 \%$,, and in KHDTK, Sebulu attack percentage was $5.21 \%$ with the percentage of dead plants $1.34 \%$ Red meranti plantation that died were ranged 6,1 to 30,0 $\mathrm{cm}$ in diameter and 7,1 to 27,5 in height.
\end{abstract}

Keywords: termites attack, Coptotermes sp, plantation, S. leprosula

\begin{abstract}
ABSTRAK
Serangan rayap Coptotermes sp. pada tanaman meranti merah (S. leprosula Miq.) menyebabkan kematian. Penelitian ini bertujuan untuk mendapatkan persentase serangan dan persentase tanaman yang mati akibat serangan rayap Coptotermes sp.. Metode yang digunakan adalah membuat plot penelitian beberapa lokasi penanaman meranti merah antara lain; PT Inhutani I, Mentawir; disekitar persemaian UUCD, Samboja; KHDTK, Sebulu dan KHDTK, Samboja. Hasil penelitian menunjukkan bahwa persentase serangan rayap pada tanaman meranti merah di PT Inhutan I, Mentawir persentase serangan sebesar 44,24\% dengan persentase tanaman mati sebesar $10,61 \%$, disekitar persemaian UUCD, Samboja sebesar 27,02\% dengan persentase tanaman mati 18,91\%, di KHDTK, Samboja persentase serangan sebesar $4,37 \%$ dengan persentase tanaman mati 1,09\%; dan di KHDTK, Sebulu persentase serangan sebesar 5,21\% dengan persentase tanaman mati sebesar 1,34\%. Tanaman meranti merah ( $S$. leprosula) yang mati tersebut diameternya berkisar $6,1-30,0 \mathrm{~cm}$ dan tingginya berkisar 7,1-27,5 $\mathrm{m}$.
\end{abstract}

Kata kunci : serangan rayap, Coptotermes sp., tanaman S. leprosula

\section{PENDAHULUAN}

Meranti merah (Shorea leprosula Miq.) merupakan salah satu jenis tanaman yang diperioritaskan untuk dikembangkan dalam pembangunan hutan tanaman dipterokarpa, terutama dalam program Tebang Pilih Tanam Indonesia Intensif (TPTII) atau dikenal
Silvikultur Intensif (SILIN) dan Program Pembangunan Model Unit Managemen Hutan Meranti (PMUMHM) di Kalimantan Timur. Jenis tanaman tersebut sudah banyak ditanam seperti di Kawasan Hutan Dengan Tujuan Khusus (KHDTK) Samboja; KHDTK Sebulu dan PT Inhutani I Mentawir. 
Tanaman meranti merah di Kalimantan Timur, sudah ditanam sejak tahun 1993/1994. Permasalahan yang ditemukan pada tanaman tersebut adalah adanya serangan rayap Coptotermes sp. yang mengakibatkan kematian. Serangan Coptotermes sp. umumnya dicirikan dengan adanya kerak tanah yang menutupi kulit batang mulai dari permukaan tanah sampai beberapa meter ke-atas. Kayu bagian dalam habis dimakan dan tinggal selapis tipis gubal di bawah kulit, se-hingga pohon mudah patah atau tumbang bila kena angin (Natawiria, 1989). Rayap Coptotermes sp.. Tergolong jenis rayap yang terganas dalam menyerang kayu dan bangunan tidak hanya di Indonesia, tetapi dibeberapa negara lain di dunia (Nandika et al., 2000).

Sehubungan dengan permasalahan tersebut diatas, maka dilakukan penelitian dengan tujuan untuk mengetahui persentase serangan dan persentase tanaman yang mati akibat serangan rayap pada beberapa lokasi penanaman meranti merah di Kalimantan Timur.

\section{METODOLOGI PENELITIAN}

Penelitian dilaksanakan di KHDTK Samboja, Kabupaten Kutai Kartanegara, PT Inhutani I Mentawir, Kabupaten Penajam Paser Utara dan KHDTK Sebulu, Kabupaten Kutai Kartanegara, Provinsi Kalimantan Timur.

Kondisi tanaman di UUCD dan PT Inhutani I Mentawir ditanam masing-masing hamparan tanaman meranti merah yang ditanam dengan jarak tanam masing-masing $2 \mathrm{~m} \times 2 \mathrm{~m}$ dan $5 \mathrm{~m}$ x $5 \mathrm{~m}$, sedangkan di KHDTK Samboja terdiri dari tiga tempat yang ditanam dalam beberapa jalur dengan jarak tanam $5 \mathrm{~m}$ x $5 \mathrm{~m}$ dan dibatasi dengan jenis pohon lain, dan di KHDTK Sebulu terdiri dari empat plot kecil yang berdekatan yang dibatasi dengan patok batas saja, ditanam dengan jarak tanam yang berbeda berturut-turut adalah $1 \mathrm{~m} \mathrm{x} 1 \mathrm{~m}, 1,4 \mathrm{~m}$ $\mathrm{x} 1,4 \mathrm{~m}, 2 \mathrm{~m}$ x $2 \mathrm{~m}$ dan $3 \mathrm{~m}$ x $3 \mathrm{~m} 1$.

Bahan yang digunakan adalah tanaman meranti merah yang ditanam tahun 1993/1994, seng alumunium untuk label pohon, sedangkan peralatan yang digunakan adalah haga, phiband dan kamera.

Menentukan tanaman meranti merah yang akan diamati pada beberapa lokasi pengamatan. Penomoran pohon menggunakan seng alumunium yang dipakukan pada batang pohon, pengukuran tinggi pohon menggunakan haga dan pengukuran diameter setinggi $1,30 \mathrm{~cm}$ menggunakan phiband dan dokumentasi penelitian menggunakan kamera. Selanjutnya melakukan pengamatan tanaman yang terserang rayap secara sensus $100 \%$, baik tanaman yang mati maupun tanaman yang tidak mati.

Untuk mengetahui persentase tanaman yang terserang dan tanaman yang mati akibat terserang rayap menggunakan rumus sebagai berikut:

$$
\begin{gathered}
\% \text { serangan rayap }=\frac{\text { jumlah tanaman yang terserang rayap }}{\text { jumlah tanaman yang diamati }} \times 100 \% \\
\% \text { tanaman mati }=\frac{\text { jumlah tanaman yang mati }}{\text { jumlah tanaman yang diamati }} \times 100 \%
\end{gathered}
$$

Tanaman yang terserang rayap dihitung tanpa memperhatikan ringan dan beratnya serangan, baik serangan rayap masih aktif maupun serangan rayap yang sudah tidak aktif lagi. Tanaman yang mati dihitung tanpa memperhatikan baru atau sudah lama tanaman ter-sebut mati akibat serangan rayap. Tanaman yang baru mati biasanya pohon masih tegak berdiri, sedangkan tanaman yang sudah lama mati biasanya pohon sudah patah/tumbang dan bahkan berupa tunggak/tunggul dan batang bagian atas sudah tidak ada lagi. 


\section{HASIL DAN PEMBAHASAN}

Serangan rayap Coptotermes sp. telah ditemukan dan menyerang tanaman pada beberapa lokasi penanaman. Serangan rayap yang masih ringan yaitu rayap membuat sarang berupa alur-alur pada batang dan belum menutup kulit batang, tanaman masih bertahan hidup. Tetapi bila serangan rayap sangat berat, dimana rayap membuat sarang pada batang dan sudah menutupi semua kulit batang, maka tanaman tidak akan bertahan hidup atau tanaman akan mati. Kematian tanaman ditandai dengan daun berwarna kuning dan daun rontok serta tanaman mati dan biasanya diikuti dengan batang pohon patah/roboh bila kena angin kencang (Gambar 1.). Jumlah tanaman, persentase serangan rayap dan persentase tanaman yang mati pada beberapa lokasi penanaman meranti merah ( $S$. leprosula) disajikan pada Tabel 1 .

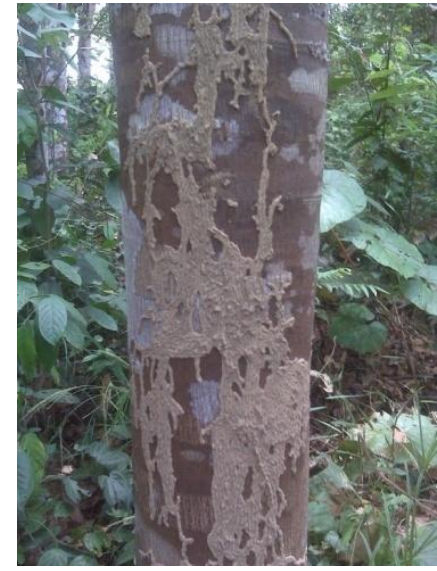

Gejala serangan

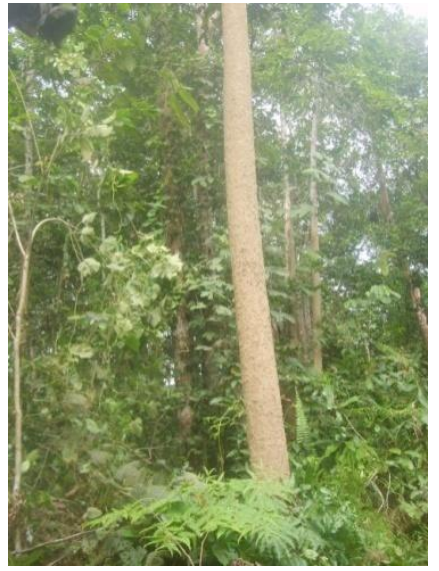

Serangan sangat berat

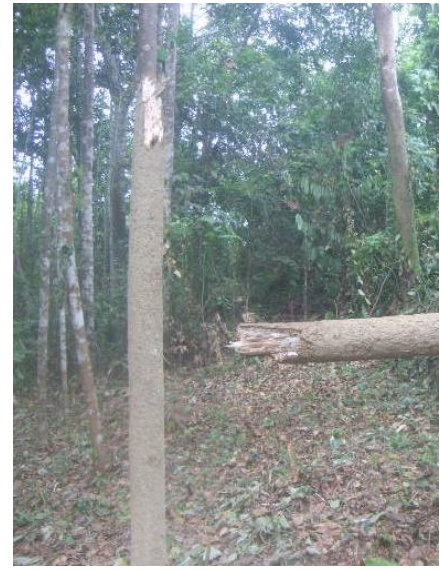

Batang pohon patah

Sumber: dokumentasi penelitian

Gambar 1. Serangan rayap Coptotermes sp. pada tanaman S. leprosula

Figure 1. Coptotermes sp. attack on S.leprosula plantation

Tabel 1. Jumlah tanaman, persentase serangan rayap dan persentase tanaman yang mati pada beberapa lokasi penanaman meranti merah (S. leprosula)

Table 1. The number of plants, the percentage of termites attack and the percentage of dead plants in several planting sites of red meranti (S. leprosula)

\begin{tabular}{ccccl}
\hline $\begin{array}{c}\text { Nomor } \\
(\text { Number })\end{array}$ & $\begin{array}{c}\text { Jumlah } \\
\text { tanaman } \\
\text { (batang) } \\
\text { Number of plant) } \\
\text { (stem) }\end{array}$ & $\begin{array}{c}\text { Persentase tanaman } \\
\text { yang terserang }(\%) \\
\text { (Percentage of } \\
\text { plants attacked }) \\
(\%)\end{array}$ & $\begin{array}{c}\text { Persentase tanaman } \\
\text { yang mati }(\%) \\
\text { (The percentage of } \\
\text { dead plants) } \\
(\%)\end{array}$ & $\begin{array}{c}\text { Lokasi penanaman } \\
\text { (Planting site })\end{array}$ \\
\hline 1 & 113 & $50(44,24)$ & $12(10,61)$ & $\begin{array}{c}\text { PT Inhutani I } \\
\text { Mentawir }\end{array}$ \\
\hline 2 & 74 & $20(27,02)$ & $14(18,91)$ & $\begin{array}{c}\text { Disekitar persemaian } \\
\text { UUCD, Samboja }\end{array}$ \\
\hline 3 & 1190 & $62(5,21)$ & $16(1,34)$ & KHDTK Sebulu \\
\hline 4 & 366 & $16(4,37)$ & $4(1,09)$ & KHDTK Samboja \\
\hline
\end{tabular}

Sumber: diolah dari data primer

Keterangan (Remarks): UUCD = Unit Uji Coba Dipterocarpaceae (Dipterocarpaceae Unit Test); KHDTK = Kawasan Hutan Dengan Tujuan Khusus (Special Purpose Forest Area) 
Pada Tabel 1 dapat dilihat bahwa persentase tanaman yang terserang rayap cukup bervariasi yaitu berkisar 4,37\% sampai dengan $44,24 \%$ dan persentase tanaman yang mati berkisar $1,09 \%$ sampai dengan 18,91 \%. Rendahnya persentase tanaman yang terserang dan tanaman yang mati pada lokasi KHDTK Samboja dan KHDTK Sebulu, hal ini disebabkan tidak semua plot yang diamati terdapat serangan rayap. Untuk KHDTK Samboja dari tiga tempat penanaman hanya dua tempat saja yang terdapat serangan rayap danuntuk di KHDTK Sebulu, dari empat plot yang ada hanya dua plot saja yang terdapat serangan rayap yaitu pada plot jarak tanam 1,4 $\mathrm{m} \times 1,4 \mathrm{~m}$ dan $3 \mathrm{~m} \times 3 \mathrm{~m}$. Selain kondisi lingkungan di sekitarnya yang mendukung perkembangbiakan rayap, juga pola tanam yang berbeda seperti jarak tanam yang lebih dekat tersebut akan lebih cepat tingkat penyebaran serangan rayap dari satu pohon ke pohon lainnya.

Tanaman S. leprosula yang mati akibat serangan rayap tersebut terdiri dari tanaman yang mati baru dan mati sudah lama. Tanaman yang mati baru biasanya pohon masih tegak berdiri dan serangan rayap masih aktif, sedangkan tanaman mati sudah lama beberapa bulan atau tahun sebelumnya bisa ditandai dengan batang pohon patah (masih ada tunggul/tunggak dan batang pohon yang patah) dan bila yang ditemukan hanya tunggul/tunggak saja, hal ini berarti serangan rayap sudah terjadi beberapa tahun yang lalu. Tunggul/tunggak pohon yang mati tetap ada, selama tunggak tersebut masih terdapat selulosa sebagai bahan makanan rayap. Terkecuali tunggak itu sudah lapuk/kropos, maka rayap sudah tidak aktif lagi atau terjadi perubahan lingkungan yang ektrim koloni bisa berpindah tempat.

Faktor lingkungan yang mempengaruhi perkembangan populasi rayap meliputi: suhu, kelembapan, curah hujan, ketersediaan makanan dan musuh alami. Faktor-faktor tersebut saling berinteraksi dan saling mempengaruhi satu sama lain. Suhu dan kelembaban merupakan faktor yang secara bersama-sama mempengaruhi aktivitas rayap. Perubahan kondisi lingkungan menyebabkan perubahan perkembangan aktivitas dan prilaku rayap. Rayap tanah seperti Coptotermes sp., Macrotermes, Odentotermes dan lain-lain memerlukan kelembapan udara $75-90 \%$ dan suhu optimum $15-38^{\circ} \mathrm{C}$ untuk perkembangan dan aktivitasnya (Nandika et.al., 2003). Berdasarkan hasil pengamatan suhu dan kelembaban di lokasi penelitian (KHDTK Sebulu), suhu di bawah tegakan $S$. leprosula adalah $20,2-28,0^{\circ} \mathrm{C}$ dan kelembapan 80,0 90,1\% (Ngatiman et al., 2011), sedangkan di lokasi penelitian lainnya kondisi lingkungan tidak jauh berbeda, karena di bawah tegakan juga ditemukan banyak serasah kering dan tumbuhan bawah yang cukup rapat.

Menurut Nandika et al., (2003), beberapa faktor yang mempengaruhi terhadap intensitas serangan rayap, diantaranya adalah kandungan selulosa, yang mana sumber makanan rayap tersebut banyak terdapat pada tingkat pohon. Selulosa merupakan konstituen utama kayu, kira-kira 40-50\% bahan kering dalam kebanyakan spesies kayu adalah selulosa, terutama terdapat dalam dinding sel (Sjostron, 1995). Kadar selulosa S. leprosula sebesar 50,76\% (Martawijaya et al., 2005). Berdasarkan hasil penelitian dari beberapa lokasi penanaman S. leprosula, jumlah tanaman yang mati, diameter dan tinggi tanaman, akibat serangan rayap cukup bervariasi (Tabel 2.).

Pada Tabel 2. dapat dilihat bahwa dari 4 lokasi penanaman $S$. leprosula, tanaman $S$. leprosula yang mati berkisar 4-16 tanaman, kisaran tinggi tanaman 7,1-27,5 $\mathrm{m}$ dan diameter 6,1-30,0 cm. Berdasarkan pengamatan di lapangan bahwa pada setiap lokasi yang terdapat serangan rayap selalu ditemukan sarang rayap dari tanah berupa gundukan tanah yang menempel pada batang pohon. Pohon/tanaman yang menjadi tempat bersarangnya rayap tersebut tidak hanya tanaman S. leprosula saja, melainkan jenis karet (Hevea brasiliensis), terap (Arthocarpus sp.) dan pohon pioner. Pohon-pohon ini ada yang terdapat di dalam plot tanaman dan ada juga 
yang terdapat diperbatasan plot dan dekat dengan tanaman meranti. Khusus untuk tanaman meranti pada tahun pertama ditemukan adanya serangan rayap dan tanaman mati, tetapi pada tahun berikutnya pada tanaman tersebut muncul sarang rayap (berupa gundukan tanah). Sarang rayap tersebut ditemukan pada beberapa tanaman meranti yang berdiameter $15 \mathrm{~cm}$ up.

Tabel 2. Jumlah tanaman yang mati, kisaran tinggi dan diameter tanaman pada beberapa lokasi penanaman meranti merah (S. leprosula Miq.)

Table 2. The number of dead plants, the range of plant height and diameter at several planting sites of red meranti (S. leprosula Miq.)

\begin{tabular}{ccccl}
\hline $\begin{array}{c}\text { Nomor } \\
(\text { Number })\end{array}$ & $\begin{array}{c}\text { Jumlah } \\
\text { tanaman yang mati } \\
\text { (batang) } \\
\left(\begin{array}{c}\text { Number dead plants) } \\
\text { (stem) }\end{array}\right.\end{array}$ & $\begin{array}{c}\text { Kisaran tinggi } \\
\text { tanaman }(\mathrm{m}) \\
\text { Range of plant } \\
\text { height }) \\
(\mathrm{m})\end{array}$ & $\begin{array}{c}\text { Kisaran diameter } \\
\text { tanaman }(\mathrm{cm}) \\
\text { (Diameter range of } \\
\text { plants }) \\
(\mathrm{cm})\end{array}$ & $\begin{array}{c}\text { Lokasi penanaman } \\
\text { (Planting site) }\end{array}$ \\
\hline 1 & 12 & $7,1-19,3$ & $6,5-17,5$ & PT Inhutani I Mentawir \\
\hline 2 & 14 & $18,3-27,5$ & $19,2-30,0$ & $\begin{array}{c}\text { Disekitar persemaian } \\
\text { UUCD, Samboja }\end{array}$ \\
\hline 3 & 16 & $9,2-19,7$ & $6,1-22,2$ & KHDTK Sebulu \\
\hline 4 & 4 & $14,4-25,7$ & $14,1-26,8$ & KHDTK Samboja
\end{tabular}

Keterangan (Remarks): UUCD = Unit Uji Coba Dipterocarpaceae (Dipterocarpaceae Unit Test); KHDTK = Kawasan Hutan Dengan Tujuan Khusus (Special Purpose Forest Area)

Dengan adanya sarang rayap tersebut menunjukkan bahwa koloni rayap semakin meningkat, karena pada diameter tanaman yang cukup besar tersebut akan tersedia cukup banyak makanan (selulosa). Dengan demikian koloni rayap akan bertahan hidup lebih lama pada tanaman tersebut. Hasan (1986), menyatakan bahwa selain menggunakan kayu sebagai sumber makanannya, rayap juga menggunakan kayu sebagai tempat hidupnya atau tempat berlindung dengan jalan menerobos bagian dalam dari kayu tersebut. Berda-sarkan hasil penelitian Zulkaidah (2005), pada jenis Dipterokarpaceae, non Dipterocarpaceae dan buah-buahan di Kebun Raya Unmul Samarinda (KRUS), ternyata kerusakan yang paling tinggi oleh rayap Coptotermes sp pada tingkat pohon daripada jenis tiang sedangkan pada tingkat pancang tidak mendapat serangan rayap. Di samping itu $S$. leprosula termasuk golongan kayu yang sangat rentan terhadap serangan rayap $C$. Curvignathus dan jenis lainnya seperti Pinus merkusii dan Acacia mangium (Rudi et al., 1999). Berdasarkan kelas awet kayu, $S$ leprosula termasuk dalam kelas IV (Katiwa, 2008).

\section{KESIMPULAN}

Rayap Coptotermes sp telah ditemukan dan menyerang tanaman meranti merah $(S$. leprosula Miq.) pada empat lokasi penanaman. Rayap tersebut menyerang tanaman yang masih hidup dan tanaman yang sudah mati. Gejala awal serangan rayap ditandai adanya kerak tanah pada batang tanaman berupa alur-alur dan alur-alur tersebut bertambah banyak akhirnya menutup semua permukaan kulit batang. Serangan rayap yang sudah sangat berat atau seluruh permukaan kulit batang tertutup oleh kerak tanah beberapa meter dari permukaan tanah dapat mengakibatkan kematian. persentase serangan rayap pada tanaman meranti berkisar 4,37 \% sampai dengan 27,02 $\%$, dengan persentase tanaman yang mati berkisar 1,09\% sampai dengan 18,91\%.

Tanaman meranti merah (S. leprosula) yang mati terserang rayap Coptotermes sp. diameternya berkisar $6,1-30,0 \mathrm{~cm}$ dan tingginya berkisar 7,1 - 27,5 m. Sarang rayap berupa gundukan tanah yang menempel pada batang pohon, sebagai indikator koloni rayap semakin meningkat. 


\section{DAFTAR PUSTAKA}

Hasan, T. 1986. Beberapa teknik pengendalian rayap di Indonesia. Ghalia Indonesia, Jakarta.

Katiwa, A.T. 2008. Sifat fisika mekanika kayu meranti merah (Shorea leprosula Miq.) hasil tanaman dari stek pucuk umur 11 tahun Pengembangan teknologi pengolahan dan pemanfaatan hasil hutan rawa gambut bagi peningkatan ekonomi masyarakat. Prosiding Seminar Nasional Masyarakat Peneliti Kayu Indonesia (MAPEKI) XI Kerjasama Masyarakat Peneliti Kayu Indonesia (MAPEKI) Jurusan Teknologi Hasil Hutan. Fakultas Pertanian Universitas Palangka Raya, Palangka Raya.

Martawijaya, A., I. Kartasujana, S.A. Prawira dan K. Kadir. 2005. Atlas Kayu Indonesia Jilid I. Badan Penelitian dan Pengembangan Kehuatanan, Bogor.

Natawiria, D. 1989. Teknik pengenalan hama hutan tanaman industri. Informasi Teknik No. 4. Pusat Penelitian dan Pengembangan Hutan, Bogor.

Nandika, D., R. Yudi dan F. Diba. 2003. Rayap, biologi dan pengendaliannya. Muhammadiyah Surakarta Press, Surakarta.

Nandika, D., R.C. Tarumingkeng, S. Suryokusumo., Y. Rismayadi dan F. Diba. 2000. Pengujian lapang umpan rayap recruit II terhadap koloni rayap tanah Coptotermes curvignatghus Holmgren (Isoptera; Rhinotermitidae). Laporan Percobaan Fakultas Kehutanan Institut Pertanian Bogor, Bogor.

Ngatiman, Armansah dan M. Budiono. 2011. Teknik pengendalian hama hutan tanaman jenis penghasil kayu pertukangan. Laporan Hasil Penelitian. Balai Besar Penelitian Dipterokarpa, Samarinda (tidak diterbitkan).

Rudi., D. Nandika, R.C. Tarumingkeng dan D. Darusman 1999. Preferensi makan rayap tanah Coptotermes curvignathus Holungren (Isoptera, Rhinotermitidae) terhadap delapan jenis kayu bangunan. Prosiding Mapeki (Masyarakat Peneliti Kayu Indonesia), Yogyakarta.

Sjostrom, E. 2005. Kimia kayu. Dasar-dasar dan penggunaan. Edisi kedua (Terjemahan oleh Hardjono Sastrohamidjojo. Gajah Mada University Press, Yogyakarta.

Zulkaidah. 2005. Identifikasi rayap yang menyerang tumbuhan pada zona pemanfaatan yang berbeda di Kebun Raya Unmul Samarinda (KRUS). Tesis Program Pasca Sarjana Universitas Mulawarman, Samarinda. 